\title{
LA MigRACIÓN COMO APRENDIZAJE SOCIAL: EL DESARROLLO DEL CENTRO Ecoturístico El Madresal en Ponte Duro, Tonalá, Chiapas
}

\author{
Migration as a Social Learning: The Development of the Ecotourism Center \\ El Madresal in Ponte Duro, Tonalá, Chiapas
}

Ana Vila-Freyer

Resumen: En este trabajo se aborda la historia de unos pescadores y sus esposas que, al agotarse el camarón, recurso de reproducción social y económica desde la fundación de su ejido en 1932, se vieron obligados a migrar a Estados Unidos. Esta experiencia se convirtió en un proceso de aprendizaje individual, cuya experiencia se transformó en un bien colectivo que les permitió crear sinergias para reconstruir su vida productiva a través de la fundación de un proyecto cooperativo de ecoturismo enclavado en la Costa chiapaneca. Dirigidos por migrantes retornados, y apoyados por entidades promotores de desarrollo, los pescadores y sus esposas han aprendido a ser empresarios pequeños, socios, y trabajadores especializados en el nuevo negocio.

Palabras clave: migración, desarrollo, remesas, cambio social.

Abstract: This work tells the story of a group of fishermen, and their wives, that having depleted the shrimp that was the natural resource they had exploited since the founding of their ejido in 1932, were forced to emigrate to the United States. This experience became an individual learning process, experience that became a collective good, which allowed them to create synergies to rebuild their productive life through the establishment of a Co-op and build an ecotourism resort located in the Costa of Chiapas. Led by former migrants and supported by public agencies to promote community development, old fishermen and their wives have learned to work as small entrepreneurs, partners and specialized workers in different areas of the new business.

Keywords: migration, development, remittances, social change.

\footnotetext{
Ana Vila Freyer, doctora en Ciencia Política por la Universidad de Montreal, Canadá. Profesora-investigadora en el Departamento de Estudios Culturales, Demográficos y Políticos de la Universidad de Guanajuato, Campus Celaya-Salvatierra, México. Temas de especialización: migración y transformación social, migración y desarrollo, migración y políticas públicas. Correo electrónico: ana6509@ yahoo.com.
}

Enviado a dictamen: 7 de septiembre de 2015. Aprobación: 15 de febrero de 2016. Revisiones: 1. 


\section{Introducción}

E n el presente trabajo se analiza el impacto que ha tenido la migración en el desarrollo de un proyecto productivo colectivo dirigido por migrantes y sus familias en Ponte Duro, un ejido del municipio de Tonalá, en la región de la Costa chiapaneca. El análisis muestra cómo la migración facilitó un proceso de aprendizaje individual y colectivo que ha apuntalado desde 2007 el desarrollo de la Cooperativa Centro Ecoturístico El Madresal (en adelante El Madresal). Los migrantes han socializado su experiencia migratoria a través de un cambio en la ética de trabajo, estructurada hasta entonces en la pesca, hacia una determinada en el sector de los servicios turísticos. Este proceso ha convertido un aprendizaje individual derivado de la migración en un bien colectivo y, con ello, se permitió la creación de un aprendizaje social con el que se explica el éxito de El Madresal. La socialización de una ética laboral aprendida en Estados Unidos ha facilitado la creación de sinergias dentro de las redes sociales y familiares de los migrantes, y de ellos, en tanto cooperativa, con agencias gubernamentales para promover un proyecto productivo colectivo que se refuerza en la formación de capital social transnacional en Ponte Duro (Evans, 1996).

La comunidad de Ponte Duro-Manuel Ávila Camacho experimentó durante la década de 1990 una serie de crisis relacionadas con el agotamiento de los bancos de camarón de los que habían vivido desde la fundación del ejido en 1932, a lo que se sumaron los impactos destructores de los huracanes Mitch, en 1998, y Stan, en 2004. La situación de emergencia forzó a los hombres a optar por dos soluciones: tratar de recuperar su forma de vida tradicional a través del cultivo rústico de camarón o emigrar a Estados Unidos. Los estudios pioneros identifican la emergencia creada por los huracanes como el factor detonante de la migración en esta región (Villafuerte y García, 2006, 2008 y 2014; Martínez, 2013). Nuestra investigación encontró que, al menos en esta comunidad, los hombres ya contaban con redes sociales en Estados Unidos, sostenidas por los migrantes pioneros que dejaron Ponte Duro al inicio de la década de 1980, diez años antes de que los huracanes Mitch y Stan afectaran la región. También, los eventos catastróficos vividos en 1998 y 2004 reforzaron la salida de jefes de familia que vivían una situación de urgencia, quienes migraron apoyándose en las incipientes redes sociales, lo que condujo a la segunda ola migratoria para buscar la sobrevivencia.

La migración dio lugar a un proceso de aprendizaje personal basado en la adaptación a las circunstancias que las personas migrantes fueran encontrando, ya que de ello dependía la supervivencia personal y familiar. Las personas migrantes se transformaron en trabajadores adaptables y flexibles, que iniciaron su proceso de cambio al caminar por el desierto, al trabajar en cualquier empleo y en cualquier condición que encontraran y al vivir como indocumentados, manteniendo los lazos familiares en sus lugares de origen. Al regresar, sus narrativas personales cambiaron, ya que aprendieron a verse a sí mismos con capacidades que iban más allá de la vida de pescadores con las que partieron. Al unirse a El Madresal convirtieron ese cambio personal en un bien colectivo, con el que los pescadores y amas de casa que construyen la cooperativa diariamente se adaptan a las nuevas condiciones de trabajo acordadas en asambleas.

Aunque la población de Ponte Duro vive en condiciones de extrema pobreza, característica de esta región de México, también ha sido capaz de conectarse con los mercados laborales de baja calificación en Estados Unidos, lo que ha contribuido a una mejora en su bienestar. Este proceso ha tenido, al menos, dos consecuencias: la primera es que los migrantes retornados han colectivizado su aprendizaje individual creando una ética de trabajo nueva en la cooperativa; la segunda es que la cooperativa está transformando también la relación tradicional entre hombres y mujeres, que trabajan y se capacitan en igualdad de condiciones.

Para analizar este caso, el trabajo iniciará discutiendo los supuestos teóricos sobre los que construimos el análisis del caso y los alcances y límites del trabajo de campo realizado en Ponte Duro. Continuamos con el análisis de los resultados de este último para destacar el proceso de transmisión del aprendizaje individual en colectivo, en el que la cooperativa sirvió como correa 
de transmisión para crear una nueva ética laboral —un bien colectivo - en la que se reforzaron las sinergias para sostener el desarrollo de un proyecto productivo como El Madresal. Concluiremos destacando los principales elementos de cambio y continuidad vividos en Ponte Duro y, en especial, los impactos que se prevé que continuarán teniendo la migración y el desarrollo en la comunidad.

\section{Migración y aprendizaje social. Creando sinergias para el desarrollo local}

El argumento de este trabajo se apoya en lo que Levitt y Lamba-Neves (2011) han llamado remesas sociales, así como en las sinergias creadas a través de las redes sociales y familiares de los mismos migrantes y en su capacidad de complementar sus esfuerzos colectivos con el apoyo tangible e intangible de agencias gubernamentales, federales y estatales (Evans, 1996). Con ello buscamos explicar la dinámica de desarrollo cooperativo creada a partir de la colectivización de una ética laboral que surge de la adaptación que vivieron los migrantes de Ponte Duro en su estancia laboral en Estados Unidos, más que centrarnos en la creación de dinámicas de desarrollo transnacional que surgen a partir del uso de las remesas en proyectos productivos, como han analizado y criticado Fernández, García y Vila (2006), Iskander (2006) y Castles y Delgado (2008), entre otros autores.

El argumento de las remesas sociales propuesto por Levitt y Lamba-Nieves asume, al menos, tres puntos: la experiencia premigratoria influye en lo que las personas migrantes hacen en el país de destino, lo que a su vez afecta sobre lo que remiten a sus comunidades de origen, lo cual queda claro, según las autoras, cuando se analiza la migración desde una óptica transnacional; la experiencia con la que los migrantes regresan moldea lo que encuentran en su trayectoria migratoria, así como lo que aportan a su retorno, $y$, finalmente, las autoras retoman los conceptos de remesas individuales y colectivas y los aplican también a los intercambios individuales y colectivos (Levitt y Lamba-Nieves 2011: 2); para ello afirman:
El impacto potencial de las remesas sociales para escalar hacia arriba y hacia afuera: las remesas sociales afectan no sólo a la cultura y a la práctica de la organización a nivel local, sino que también pueden influir en los cambios regionales y nacionales [...] Por otra parte, las remesas sociales individuales y colectivas también influyen fuertemente en la forma en que los grupos organizados se relacionan con las estructuras del Estado y fomentan sinergias "estadosociedad (Evans, 1996)"

Como veremos más adelante, los migrantes de Ponte Duro regresaron a su comunidad con una nueva visión de sí mismos que, entre otras cosas, implicó la creación de una nueva ética laboral. Llegaron provistos de un aprendizaje individual que aplicaron al trabajo colectivo de la organización: el trabajo en espacios cerrados siguiendo un horario establecido y el pago por horas y no por jornada, lo que refuerza la idea de que la mejora personal y familiar está aparejada con el trabajo duro. Del mismo modo, sin tomar en cuenta su estatus migratorio, las personas fueron capacitadas por las empresas para reforzar su posición dentro de ellas, su liderazgo, así como su flexibilidad laboral. Todo este aprendizaje individual escaló hacia arriba en un proceso de aprendizaje social, hasta convertirse en lo que Evans llama bienes colectivos intangibles (1996: 181).

Este escalamiento también se dio hacia afuera, con las instituciones públicas. El desarrollo de un centro ecoturístico coincidió con el fracaso de cooperativas para sembrar camarón en el mar, con el retorno de los migrantes y con el interés de agencias gubernamentales por desarrollar proyectos productivos comunitarios en el sureste de México, Chiapas incluido (Bellinghausen, 2008). De esta manera se reforzaron los vínculos y reglas de trabajo dentro de la cooperativa, al tiempo que se construyeron sinergias con agencias gubernamentales que fueron apoyando las distintas etapas del proyecto. Estos vínculos son categorizados por Evans como complementarios y enraizados - complementarity y embeddedness - (1996: 179). El primero - complementariedad - se refiere a la conceptualización de relaciones de apoyo mutuo que 
se sostienen en una clara división del trabajo entre instituciones públicas y privadas. ${ }^{2}$ A su vez, el segundo - enraizamiento - lo define como los vínculos que conectan a los ciudadanos con los funcionarios públicos en los distintos espacios públicos y privados para promover el desarrollo comunitario. Este proyecto es exitoso porque se basa en redes sociales horizontales sólidas, con las que se construyen y legitiman liderazgos — de exmigrantes - ${ }^{3}$ y se crean vínculos de confianza intragrupal, así como redes verticales - e intergrupales - con agencias gubernamentales para obtener los recursos tangibles e intangibles con los que los cooperativistas han sostenido el desarrollo de El Madresal. Finalmente, lo interesante de este proyecto es que se trata de un proyecto productivo colectivo ${ }^{4}$ que se construye con el trabajo cooperativo de las 42 familias que son propietarias de El Madresal.

\section{Metodología}

La región de la Costa fue seleccionada porque, al revisar la expedición de matrículas consulares entre 2006 y 2011 , descubrimos que, en Chiapas, después del Soconusco era la segunda región de origen de las personas que más demandaron este documento de identidad en los consulados mexicanos en Estados Unidos (SRE, 2007) y era también la región menos estudiada de las que habían registrado migración internacional, según intercambios con Daniel Villafuerte, que amablemente aceptó asesorarnos durante la definición y ejecución del proyecto. Elegimos Ponte Duro como estudio de caso por una serie de eventos afortunados. Descubrimos El Madresal al realizar un trabajo exploratorio y porque nos hospedamos en el lugar. En conversaciones con las personas, nos dimos cuenta de que siete de los diez miembros del Consejo Directivo de la cooperativa eran migrantes que habían regresado a su comunidad una vez salvada la urgencia creada por los huracanes. Este hecho se repitió al platicar con los hombres miembros del Comisariado Ejidal, en el que la mayoría tenía experiencia migratoria. El trabajo exploratorio lo realizamos en dos visitas aisladas en distintas comunidades en la Costa chiapaneca en febrero y abril de 2012.

Para recabar la información empírica utilizada en este texto seguimos una metodología mixta. Encuestamos a 221 personas tocando de puerta en puerta en todas las viviendas de la comunidad durante las dos semanas que van del 10 al 25 de julio de 2012 Por el horario en el que las realizamos, entre las 9 y 17 horas, tuvimos un sesgo de más respuestas de mujeres - $54 \%$, frente a $46 \%$ de hombres - y las edades de las personas encuestadas oscilaron entre los 18 y los 75 años. Seleccionamos además diecisiete personas —exmigrantes, líderes municipales, líderes de Iglesias y los dos hombres más viejos del ejido- para hacerles entrevistas semiestructuradas; de éstas, doce fueron a miembros de la Cooperativa de Ecoturismo El Madresal, entre las que incluimos hombres y mujeres con y sin experiencia migratoria. Como estuvimos hospedados durante dos semanas en El Madresal, tuvimos oportunidad de convivir con los cooperativistas. En estas entrevistas les pedimos que nos contaran su historia, la de la comunidad, su relación con la migración - su experiencia como migrante, como miembro de una familia migrante o como padre o madre de un migrante - en caso de tenerla, así como su participación en la organización de la cooperativa. Algunas entrevistas se realizaron de manera individual y otras en grupos de dos o tres personas.

\section{Crisis, migración y aprendizaje social en Ponte Duro}

La comunidad de Ponte Duro, en el municipio de Tonalá, se encuentra en la región de la Costa chiapaneca, muy cerca de los lugares de paso que utilizan los centroamericanos para alcanzar el tren en Arriaga, el municipio vecino. ${ }^{5}$ La movilidad hacia el norte inició durante la década de 1980, cuando los pobladores empezaron a escuchar acerca de los beneficios de la migración y se decidieron a probar suerte. ${ }^{6}$ No se puede decir que los emigrantes de Ponte Duro hayan llenado algún nicho de mercado en alguna región de Estados Unidos ni que cuenten con un circuito sólido en aquel país, puesto que los habitantes de esta 
pequeña comunidad se han establecido en al menos diecisiete entidades del país del norte. ${ }^{7}$ Aunque falta profundizar en el proceso de formación de las redes sociales y familiares, las entrevistas nos dejaron ver que los migrantes pioneros facilitaron, si no financiaron, la movilidad de parientes y amigos, sobre todo durante los eventos catastróficos vividos en la comunidad provocados por los huracanes Mitch, en 1998, y Stan, en 2004, que vinieron a reforzar la migración internacional de los jefes de familia por la urgencia de sobrevivir. En el verano de 2012, el 37\% de la población de Ponte Duro tenía experiencia migratoria y, de este porcentaje, el $11 \%$ no regresó. ${ }^{8}$

Ponte Duro-Manuel Ávila Camacho es una comunidad que en el censo de 2010 registró 1778 habitantes, 124 menos de los inscritos en su punto más alto, el año 2000 (INEGI, 2001 y 2011). Los registros de las matrículas consulares muestran una pérdida de población joven, tanto masculina como femenina, que tiene estudios terminados en secundaria y preparatoria (Vila, 2013). ${ }^{9}$ La pérdida de población masculina empezó a registrarse en el lustro que va de 1995 a 2000, mientras que la pérdida de población femenina se registró a partir de 2005. La comunidad, colonia o ejido - como la refieren de manera indistinta sus habitantes- está ubicada a orillas de la playa, a 45 kilómetros de Tonalá, la cabecera municipal. Apoyados en la memoria de las personas de mayor edad, refieren que el ejido lo fundaron 63 familias entre 1932 y 1936, cuando recibieron veinte hectáreas cada una para trabajo agrícola, más un área común para construir sus viviendas. ${ }^{10}$ Lograron la formalización durante el gobierno de Manuel Ávila Camacho (1940-1946) y por ello adoptaron el nombre del expresidente.." Según las mismas personas, actualmente viven en el ejido alrededor de 450 familias, de las cuales 145 siguen siendo ejidatarias.

A pesar de la pobreza, Ponte Duro es uno de los pocos ejidos de Tonalá en los que en 2012 todavía funcionaba una vieja clínica de salud, heredada del sistema IMSS Solidaridad, y cuenta con un Colegio de Bachilleres activo desde 2008. La encuesta realizada mostró que el $88 \%$ de las jefas de familia recibía recursos del programa Oportunidades y el 93\% se había inscrito en los últimos siete años en el Seguro Popular. ${ }^{12}$ Los comisariados ejidales, que a excepción de dos personas tenían experiencia migratoria, se habían organizado para obtener recursos del Programa de Empleo Temporal de la Secretaría de Desarrollo Social (SEDESOL) para pavimentar algunas de las calles secundarias de la comunidad; sólo las dos calles principales estaban pavimentadas. De las 221 personas encuestadas, el 24.6\% no sabía leer ni escribir y el 23.8\% dijo haber terminado alguno de los tres primeros años de primaria.

\section{Ética de trabajo: la pesca como forma de vida}

La población de Ponte Duro vivió de la pesca del camarón desde su fundación en los años treinta hasta la década de los ochenta del siglo pasado, por lo que no se pidieron nuevas dotaciones de tierra a pesar del crecimiento poblacional. Las personas hoy de mayor edad, hijos de los fundadores y la primera generación que nació y creció en Ponte Duro, recuerdan que durante las décadas de los sesenta y setenta vendían camarón por toneladas, incluso a personas que llegaban de Estados Unidos en avionetas para comprar el producto. Esta actividad permitió a dos generaciones vivir de la pesca hasta su agotamiento en la década de los ochenta. Los miembros de la tercera generación, los bisnietos de los fundadores, son los pioneros, los primeros migrantes internacionales que, siguiendo los pasos de Apolonio Pineda, el primer migrante de quien se tiene memoria decidieron salir de la comunidad para probar suerte en Estados Unidos.

El grupo de personas que hoy tienen entre 40 y 59 años aprovechó los contactos abiertos por los pioneros para migrar y atender las necesidades creadas por los huracanes una década después. Algunos ya habían salido de la comunidad a las ciudades cercanas para estudiar o buscar un trabajo en la ciudad de México o en zonas petroleras y turísticas de Veracruz, Campeche y Quintana Roo; también la generación que se encuentra entre los 35 y 44 años halló en la migración acceso a recursos para comprar tierras y animales para construir 
oportunidades económicas en México. La migración internacional está alimentada hoy en día por hombres y mujeres por igual, de entre 17 y 25 años, quienes al lograr mayor nivel educativo que sus padres se desesperan por la falta de oportunidades que Ponte Duro les ofrece, ante las expectativas que un mayor acceso a la educación genera en ellos y que eligen satisfacer trabajando en Estados Unidos.

El que la comunidad viviese mayoritariamente de la pesca y comercialización del camarón estructuró también una ética laboral en la que, como se ilustra en el epígrafe con el que se inicia este texto, los hombres jefes de familia lograban en unas horas de trabajo, al aire libre y sin días fijos ni horarios establecidos, ingresos suficientes para atender las necesidades básicas de sus familias, que muchas veces también participaban de la pesca y se alimentaban de la pesca residual. Los hombres pescaban camarón y las mujeres lo limpiaban para venderlo.

\section{Confrontando la crisis del camarón: las dos soluciones}

El agotamiento de los bancos de camarón empezó a manifestarse al inicio de los años ochenta y ha aumentado el empobrecimiento sostenido de la población. Para enfrentar la primera crisis, las familias de Ponte Duro optaron por dos soluciones: emigrar a Estados Unidos o tratar de recuperar el estilo de vida que habían conocido desde la fundación de la colonia sembrando camarón, que producirían en criaderos rústicos. Como mencionamos, el primer migrante del que se tiene memoria es Apolonio Pineda, quien salió de la comunidad entre 1978 y 1979. Recuerda Diego, el agente municipal de Ponte Duro:

Los primeritos emigrados de acá fueron una familia que se apellida Pineda. Ellos fueron los primeros migrantes hace como unos treinta o cuarenta años [...] Ellos empezaron a decir que en los Estados se gana bien, pagan por hora, y miraron la gente de aquí que empezaron a ganar y de ahí, pues, la gente empezó a migrar [...] La gente empezó a migrar en 1982, más o menos, por la simple y sencilla razón de que el mar ya no da lo suficiente, año con año se ha ido acabando y ahorita no tenemos ningún tipo de negocio. Por esa razón la gente ha emigrado buscando un futuro mejor, que es allá en el norte (Diego, 12 de julio de 2012).

Don Jorge explica que:

La gente [no se organizaba para irse] así nomás, sólo a veces agarraban mochila al hombro. No se organizaba, nunca se organizóla gente. Después, como en 1986, fue la amnistía. Muchos en Estados Unidos se hicieron residentes y se llevaron a su familia, la recogieron [... Cuando el huracán] ya mucha gente había migrado, de hecho ellos jalaron a la gente con problemas, como un $20 \%$ del pueblo, tal vez más. Algunos volvieron, otros ya no, hay gente que tiene [fuera] como quince o veinte años y no han regresado (Jorge, 12 de julio de 2012).

La segunda forma de enfrentar la crisis que surgió por el agotamiento del camarón consistió en sembrarlos en el mar tras criarlos en viveros rústicos. En este nuevo proyecto se involucraron cien miembros de la Cooperativa 20 de Noviembre, la que abandonaron para formar una nueva cooperativa - aunque todos los entrevistados la mencionaron, no preguntamos el nombre de la nueva cooperativa- Tras ello iniciaron las sinergias con agencias gubernamentales que contribuyeron con apoyo material y técnico de la Secretaría de Medio Ambiente y Recursos Naturales (SEMARNAT) o la de Pesca — quizá las dos, no está claro en la memoria de los entrevistados-, y se construyeron granjas o viveros rústicos con los que cultivaron camarón para luego sembrarlo en el mar. Las condiciones ambientales, el desconocimiento técnico, la falta de asesoría suficiente por parte del gobierno o todo junto, contribuyeron a que el proyecto fracasara. Don Paulino recuerda:

En una asamblea dijimos de hacer granjitas, que quién quería [entrar]. El presidente [de la cooperativa] nos decía: "sí, háganla". Y fuimos a limpiar y a empalar. Empezamos como dieciocho gentes [...] pensamos que las granjitas darían resultado y empezamos a hacer un 
zango de dos metros a pura pala para que el camarón tuviera donde crecer, y sí, vimos que estaba llena la playita y el camaroncito sí estaba [...] Sí, el primer año sacamos como unos cien kilos de camarón, a la próxima [temporada] le metimos como un millar de larvas pero no funcionó, casi todo se murió, se salió [...] De ahí dijeron que se iba a usar el exceso, para eso se dragó aquí, ahí anduvimos cooperando entre todos, una cooperación de cuatrocientos [pesos], que la máquina nos cobraba mil pesos la hora. Q a medias el trabajo y dábamos vueltas, que se había ido el de la máquina y cómo le íbamos a hacer para terminar. De ahí volvió a venir y volvimos a cooperar para que se terminara y sí, se terminó. Ya cuando se había terminado todo, los de ahí ya no querían trabajar, querían nada más ganar pero se les marcó el alto, que los que habíamos trabajado éramos nosotros, y así fue como se fue la gente (Paulino, ll de julio de 2012).

\section{De la pesca de camarón a la hotelería: el nacimiento del Proyecto Ecoturístico El Madresal}

Es incierto el tiempo que dedicaron los miembros de la nueva cooperativa al proyecto de cultivar camarón. Algunos dicen que fueron seis meses, otros dos años. Recuerdan que ese proyecto inició en 1997 y que el proyecto ecoturístico comenzó el l de enero de 2008. Esa década transcurrió entre las crisis creadas por los dos huracanes y la intensificación de la emigración. Entre los hombres surgió la idea de construir una palapa en la que se vendiera pescado asado a los turistas. De los cien hombres que habían iniciado la nueva cooperativa, quedaban solamente 56, quienes en una reunión decidieron invitar a sus esposas para que se encargaran de cocinar y apoyar en el nuevo negocio.

No está muy claro cómo transitaron de las palapas de comida al proyecto ecoturístico, pero con el cambio en el objetivo se buscaba aprovechar un lugar que era conocido y visitado en la región durante las vacaciones y las fiestas de fin de año y de Semana Santa. Se trataba de construir cabañas para que, además de comer, los visitantes también se quedaran a dormir, de manera que el negocio fuera permanente. El canal que se había construido para tratar de reducir la corriente del vivero de camarón se utiliza desde entonces como muelle para cruzar, en una lancha, el trozo de mar que divide el acceso principal de un terreno de dos hectáreas en las que desarrollarían el proyecto.

Doña Daisy, que había migrado con su esposo a Estados Unidos y posteriormente regresó, recuerda:

Cuando vimos la idea de las granjitas, nuestros esposos, junto con otros compañeros, vinieron y nos dijeron que íbamos a poner unas palapas sencillas, y se pararon [construyeron] y empezó a venir poca gente. Nosotros cooperábamos para las palapas y hacíamos venta [poniendo dinero] de nuestra bolsa. [...] Fue la idea del señor Silvino [que decía que] a lo mejor eso diera resultado, y así fue como los compañeros ya hicieron su reunión y dijeron que todo aquel que quisiera meter a su esposa al grupo lo podía hacer. De ahí que nuestros esposos nos fueron a avisar y les dijimos que sí para que se hiciera eso, para que [trabajáramos] de cocinera y toda la cosa [...] Esto era una parcela, dos hectáreas de mi esposo, y la compraron recolectando el dinero entre todos [...] Ahí cooperábamos hombres y mujeres [...] Cuando comenzamos, comenzamos de la nada, no teníamos dinero, así que nosotras las mujeres cooperábamos con los trastes porque no teníamos dinero [...] Trajimos trastes, tazas, platos, todo, todo. Empezamos a prestar y a trabajar con los hombres. Nosotras cargábamos las palmas, ellos se ponían a construir y nosotras ayudábamos (Daisy. 10 de julio de 2012).

Su hijo Fabián, el presidente de la cooperativa, recuerda que:

Cuando iniciaron lo de los camarones yo estaba fuera [en Estados Unidos]. Cuando yo llegué, encontré que no les daba. Ya se estaban desanimando porque no veían un futuro o una cosecha, no veían resultado de la visión que tenían. Cuando yo llegué estaban en ese proceso de reorganización, entonces pedí oportunidad de agregarme y ya fue que estoy aquí. Yo alcancé a tener un año de producción de 
camarón pero no era suficiente, pero le dimos el giro buscando una alternativa, que era el turismo [...] Ocurrió porque aquí eran terrenos federales y era un balneario totalmente local. Sólo se usaba del día lo de enero, el jueves, viernes y sábado de gloria, la Semana Santa, cuatro días al año en total. Nosotros pasábamos gente, teníamos un motorcito y mirábamos que era más o menos rentable, que sólo se necesitaba infraestructura y ponía yo un negocio acá y vendía yo comida, botanas para los [turistas] locales y era nada más cuatro días al año. Entonces de ahí se prendió el foco, de ahí que pensamos en buscar por el turismo, de ahí nacieron las ideas de la gente que sólo buscaba una oportunidad [...] Entonces, viendo que ese lugar ya era visitado por gente local de la comunidad y ya teníamos el acceso, dijimos "vamos a probar", y luego los representantes de la presidencia municipal empezaron a apoyarnos, y dijimos que por qué no practicábamos turismo (Fabián, 16 de julio de 2012).

Otros testimonios aseguran que la idea de construir un centro ecoturístico surgió por recomendación de los representantes de las agencias de gobierno, o que la trajeron los migrantes que regresaron entre 2007 y 2008 y son quienes han dirigido la cooperativa desde entonces. El hecho es que las redes sociales y familiares de los cooperativistas se reforzaron con los migrantes que regresaron. Don Paulino explica, por ejemplo, que el trabajo se ha organizado en dos grupos desde entonces, un día trabajaban en la cooperativa y el otro pescaban para comer; también, que hicieron una olla colectiva en la que todos aportaban y comían juntos, como una familia. Al tiempo que reforzaban los lazos de amistad y confianza entre ellos, los cooperativistas tenían vínculos (embeddedness) con agencias gubernamentales responsables de promover el desarrollo comunitario en Chiapas. Con ellos construyeron sinergias para el desarrollo del proyecto y obtuvieron los apoyos tangibles para financiar la construcción del centro ecoturístico, así como los recursos intangibles con los que se han ido especializando en diferentes áreas del negocio a través de la capacitación.

\section{Experiencia migratoria, adaptación y aprendizaje individual}

De quienes integraban la mesa directiva de la Cooperativa de EcoturismoEl Madresal, fueronmigrantes el presidente, el vigilante, el tesorero y el delegado, es decir, cuatro de los diez miembros. Los miembros del Consejo Administrativo, así como los responsables de las comisiones, también migraron a Estados Unidos y volvieron. En total, 12 de los 42 miembros de la cooperativa, el 30\%, tiene experiencia migratoria. Otros miembros tienen algún familiar en Estados Unidos, aunque ellos no hayan migrado directamente. Cuando se les preguntó sobre las siete posiciones de control que ocupan los exmigrantes, lo consideran una casualidad, aunque explican que la migración les cambió la forma de ver el trabajo y reforzó su capacidad de adaptación y de organización.

Las personas con experiencia migratoria que entrevistamos reconocen que cambiaron la forma de verse a sí mismos y a su comunidad. Saben que su narrativa personal ya no corresponde con la de los pescadores que se fueron a Estados Unidos. Esta nueva narrativa se debe a que la migración les permitió acceder a procesos de capacitación con los que sustituyeron la falta de educación formal que tenían antes de partir, porque desarrollaron capacidades de organización y planeación que les permitieron llevar una vida transnacional, con un diferente manejo de su tiempo y recursos, lo que les permitió sobrevivir en Estados Unidos y sostener a su familia en México. Los migrantes también desarrollaron lo que hemos llamado una "nueva ética de trabajo": cambiaron la identidad que habían desarrollado por realizar un trabajo poco estructurado, al aire libre y socialmente transmitido como pescadores, por una distinta, al realizar trabajos encerrados en fábricas, en donde había que cumplir un horario, capacitarse y recibir un pago por hora, hecho que reforzó en ellos la idea de que el bienestar propio y de sus familias depende directamente del esfuerzo personal. Aprendieron a trabajar regularmente y a hacerlo en un horario, además de que reconocen que la capacitación les ayudó a adaptarse a las condiciones laborales que iban encontrando. Todo esto lo englobamos en el concepto de remesas sociales. 
Fabián, el presidente de la cooperativa, describe su experiencia de la siguiente manera:

[Los migrantes] mostramos una diferencia de capacidades y de deseos de superación entre los demás. Mi deseo es contagiar a los demás [...] Debemos rescatar esos conocimientos de las empresas [... La migración nos dio] seguridad, creo que la gente que migra y la gente que ha estado en otros lugares sí tiene esa seguridad de lo que hace porque lo ha aprendido. Ya ve que en las compañías te capacitan y, en lo que a mícorresponde, por ejemplo, yo en la compañía donde estaba, pues yo quería ser líder también y me estaba preparando. Ya estaba estudiando inglés, ya estaba yo entrenando con grupos a manejarlos, ya me dejaban. Y creo que sí, [la migración] hace esa diferencia de la gente que no ha salido de la comunidad, la gente que sólo se ha dedicado a la pesca, pues desconoce el trabajo en empresa y eso te da seguridad, yo creo que sí hay una diferencia y hay una apertura total, hay como una perspectiva mejor de los propósitos y objetivos como líder [...] Yo creo que el emigrar a Estados Unidos te hace ver diferente las cosas. Antes, si tenías perspectivas, pues eran pocas ino? y se te cerraba el mundo. Por haber migrado te das cuenta de que todo se puede hacer, sólo hay que arriesgar, porque nos arriesgamos a ir a la frontera y yo, por ejemplo, caminé tres días en el desierto. Si no arriesgas, no ganas (Fabián, 16 de julio de 2012).

Este aprendizaje y la capacidad de adaptación individual se han contagiado a la organización del trabajo en la cooperativa, de modo que se ha convertido en un bien colectivo. El aprendizaje y la experiencia individual se han traducido en un aprendizaje social que se refleja en el reglamento y en las reglas de organización del trabajo. Efraín, el tesorero, explicó que el trabajo se organiza de la siguiente manera: todos tienen que trabajar de manera disciplinada, seguir un horario, llegar a tiempo y ser responsables de sus áreas; también explicó que las faltas y retardos se penalizan y pueden conducir a la expulsión. El espíritu de responsabilidad colectiva se evidenció en las entrevistas, en la motivación y en el espíritu de servicio que manifestaron los entrevistados $y$, sobre todo, en el orgullo que mostraron por ser propietarios .

El proceso de aprendizaje colectivo transmitido a partir de la experiencia migratoria de los dirigentes de la cooperativa se refuerza a través de las capacitaciones que reciben periódicamente y que sustituyen la falta de educación formal de los cooperativistas. A decir de Fabián, se trata de "reconvertir un grupo de pescadores tradicionales, y sobre todo de amas de casa, a empresarios". Buena parte de los cursos los ha impartido la Secretaría de Turismo en las instalaciones de El Madresal. Los dirigentes de la cooperativa afirman que se han apuntado a todos los cursos que han podido para especializarse en áreas relacionadas con el negocio o aprender otras actividades, lo que ha reforzado los vínculos de complementariedad y las sinergias entre las agencias gubernamentales y las redes sociales existentes en El Madresal encaminados hacia el desarrollo comunitario. Efraín, un exmigrante y tesorero de la cooperativa, señaló:

Nuestra intención es que estudien. Ustedes [entrevistadores] tienen una forma muy rápida de desarrollar las cosas. Nadie aquí ha estudiado, no hay ni un licenciado, ni un abogado, arquitecto o ingeniero, no hay nada [...] cuando mucho, algún compañero tiene un año de prepa, de ahí quizá hasta un año de secundaria terminada, y algunos de los compañeros que son de las personas más grandes no tienen ni primaria, no saben leer ni escribir. Y sin embargo están trabajando y ahí los adaptamos poco a poco. El más joven de la cooperativa tiene 26 años y el más viejo 85 (Efraín, 12 de julio de 2012).

Aunque el proceso ha sido lento, las mujeres empiezan a reconocer la importancia de la capacitación y de su participación en el proyecto. Hasta cierto punto, la capacitación ha reforzado una noción de equidad laboral. Doña Daisy señaló:

[...] para aprender, nos capacitan. Nos capacitan igual [a hombres y mujeres]. Así, ya hay hombres que 
saben de la cocina y ya estamos capacitadas para ser cocineras, para ser meseras, recamaristas, para todo lo que necesitemos. Los cursos los recibimos aquí. El trabajo lo dividimos entre hombres y mujeres. Nosotras como amas de casa fuimos aprendiendo [...] Yo, por ejemplo, era cocinera de asar pescado y ahora ya no [...] estamos de recamareras. Cambiamos las posiciones hasta donde aguantan las mujeres, nos rotan cada ocho meses o un año. Ahorita ya casi todos los hombres andan de meseros, las mujeres ya no [... hay especialización de funciones] porque ahorita ya está la cocinera, el de la barra, el de las bebidas [...] Como todos somos socios, todos tenemos que trabajar según nuestras fuerzas y los beneficios se reparten igual. Si toca diez pesos, nos toca a cada uno y nadie va a decir pío... nadie es dueño, todos somos socios iguales (Daisy, 10 de julio de 2012).

Lo interesante de la visión de doña Daisy es que encierra un aprendizaje de igualdad de género, así como de adaptación laboral. El que los hombres sepan de cocina y sean meseros representa para ella un cambio en los roles tradicionales por los que, de hecho, sus maridos las invitaron a formar parte de la cooperativa. Aunque el proceso de cambio de rol, de amas de casa a socias en igualdad de condiciones que sus maridos, se reconoce como algo muy difícil, la capacitación está abriendo esa posibilidad. Las mujeres se reconocen como socias y han aprendido a dominar sus puestos de trabajo y a ser trabajadoras flexibles y adaptables. También se han acostumbrado a recibir un salario equivalente al de los hombres.

Este cambio es menos visible en los hombres mayores porque algunos siguen añorando su vida anterior. Veamos el ejemplo de don Paulino, que tiene una hija en Estados Unidos y él se encarga de educar a sus nietos, aunque nunca ha salido de Ponte Duro:

Cuando no teníamos cursos [educación formal] estábamos bastante cerrados de la cabeza. Pero con los cursos nos han explicado, nos han dicho y nos ha quedado bastante [...] Pues, lo que he aprendido, a ser respetuoso con la gente, a respetar principalmente a los turistas que vienen. Todo es muy valioso en los cursos que nos han dado [...] Nos dieron el curso de modernizar, el de calidad en el servicio y otro curso del restaurante, también de alimentación, de bebida, todo eso nos han dado. También nos dieron el de mesero, nos dieron nuestros reconocimientos [...] Yo ya fui ayudante del de la barra, ayudé a destapar, fui acuchillador de pescado cuando muy empezamos, me la eché de mesero unos meses, como nos habían dado curso, pero como lo van cambiando ya me meto a la motoreada, a la lancheada, siempre vamos aprendiendo un poco [...] Lo que más me gusta es ser lanchero. Sí, me gustaría ser lanchero, pero a veces nos falta un poquito de vocación e irle explicando a los turistas bien, y en eso hay cuatro compañeros que se prepararon para el curso de guías, y nosotros no nos hemos preparado todavía (Paulino, ll de julio de 2012).

A diferencia de doña Daisy, don Paulino sigue extrañando el agua, la vida de pescador en la que nació, creció y sostuvo a su familia. A pesar de ello, es una de las personas más amables y entusiastas del proyecto y ha trabajado fuerte para construir un patrimonio para sus hijos y nietos. Escogimos los ejemplos de doña Daisy y don Paulino porque representan el proceso de aprendizaje social que se refuerza con la capacitación y la flexibilidad laboral con la que se construye El Madresal, donde los socios identifican sus áreas de especialidad y conocen las funciones básicas de las distintas áreas del negocio. La identidad de hombres y mujeres, en especial la que deriva de su trabajo y posición en la cooperativa, ha sufrido cambios importantes porque los pescadores han aprendido a asumirse como propietarios, y porque los hombres han aceptado el trabajo y la presencia de las mujeres como sus iguales. Ellas, por su parte, han ampliado el trabajo del hogar para especializarse en distintas áreas relacionadas con la hotelería. Aunque muchas de sus funciones sigan definidas según el género - son recamaristas, encargadas de limpiar, lavar la ropa o cocinar-, aprenden a trabajar codo a codo con los hombres y trabajan por igual como meseros y 
cocineros. Todos, hombres y mujeres, han desarrollado una gran capacidad de aprendizaje social al cambiar la visión que tenían de ellos mismos y al asumirse como parte fundamental de la cooperativa.

\section{Del refuerzo de las redes internas y el escalamiento hacia arriba}

El Madresal es un proyecto que ha sabido combinar la experiencia migratoria de sus miembros, el refuerzo de sus redes sociales y la construcción de sinergias con agencias encargadas de promover el desarrollo comunitario. Ésta, creemos, es una diferencia fundamental con los experimentos que se han realizado en Guanajuato o Zacatecas, en la región tradicional de migración en México (Durand, 2003), donde agencias gubernamentales, estatales y federales, han ensayado estrategias para promover el desarrollo comunitario a través de clubes de migrantes o del uso efectivo de remesas. La mayor parte de estos esfuerzos han fallado porque con ellos se intenta promover el uso de remesas económicas, familiares o colectivas, en proyectos de desarrollo definidos en un contexto transnacional, pero no se distingue entre proyectos productivos y proyectos sociales (Iskander, 2006; Fernández, García y Vila, 2006).

Esa dinámica se diferencia de la implementada en El Madresal porque, como hemos señalado, se trata de un proyecto productivo colectivo al estar conformado como una cooperativa. Aunque los cooperativistas han tenido que aprender elementos básicos de trabajo colaborativo por la naturaleza de su negocio turístico, la noción de colectividad continúa, aunque transformada, porque perdura la forma tradicional de organización que se ha desarrollado en Ponte Duro desde su fundación, primero como ejido, después como población de pescadores. En las primeras etapas organizativas, los recursos tangibles para el desarrollo del proyecto se obtuvieron con una combinación de aporte individual - una vez fracasado el proyecto de los viveros rústicos, se aportó una nueva cooperación de quinientos pesos para construir las palapas para vender comida-, con apoyo sustancial del Gobierno y con el trabajo manual - recurso intangible- de las mujeres y hombres cooperativistas.
El desarrollo de El Madresal combinó aportes otorgados por la Secretaría de Desarrollo Social (SEDESOL) y la Comisión para el Desarrollo de Pueblos Indígenas (CDI) destinados a salarios por empleo temporal y a la construcción de instalaciones. Los cooperativistas decidieron en asamblea ceder los recursos que les correspondían de empleo temporal para la construcción de infraestructura, aporte que combinaron con el trabajo colectivo de hombres y mujeres y que utilizaron para comprar la parcela en la que construyeron su proyecto. En el momento de realizar la investigación, habían invertido cuatro años en la construcción del mismo y estaban orgullosos de haber logrado, unos meses antes, un ingreso semanal continuo. Al final, como buenos pescadores, un día pescaban y otro trabajaban en el proyecto, por lo que comida no les faltaba. Don Paulino ofreció un recuento detallado de la forma en como "bajaron" los recursos tangibles para el proyecto y los combinaron con su esfuerzo personal:

El señor que era dueño de la parcela nos la vendió, dos hectáreas de terreno para que pudiéramos tener los baños y las cabañas. Después, gracias a Dios, nos apoyó SEDESOL, nos dio el apoyo de unas cabañas. SEDESOL nos dio 800 u 850 [mil pesos], una cosa así. Ellos tenían el proyecto que querían, pero una cabaña de esas nos salía en ochenta mil pesos, así que nos daban para cuatro o cinco cabañas, también nos dieron para empleo temporal [...] los cincuenta pesos [por día del programa de Empleo Temporal] que ganábamos nosotros, que era el [salario] mínimo, lo volvíamos a invertir para pagar esto [...] Luego, como que se enojaron los señores que vinieron porque nos dieron dinero para cuatro cabañas, pero nosotros hicimos nueve. Pero a nosotros no nos tocó dinero, nada, todo lo invertimos porque queríamos crecer [...] tenemos trabajo y sacamos poco, lo invertimos, los días de descanso vamos a pescar y uno o dos kilos de camarón, pues lo agarramos [...] Como nosotros lo manejamos, hicimos nueve cabañas y compramos el terreno que tenemos porque era así, lo estiramos; y si lo hubiera manejado el ayuntamiento, nada más las cuatro cabañas, ni el terreno lo hubiéramos pagado 
porque salía en ochenta [mil pesos] cada cabaña. [Cuatro años después, en 2012] ya son diecisiete cabañas. En el segundo que vino igual venía para cinco, pero nosotros hicimos otras siete o seis cabañas (Paulino, ll de julio de 2012).

Continúa su recuento:

Hemos bajado fondos de tres a cuatro millones de pesos, un millón por año, de distintos proyectos. Los compañeros van, están conectados con los de allá arriba, ellos les enseñan en dónde pueden pedir o a dónde pueden ir a llevar los proyectos. Ellos van con el presidente municipal, hace los proyectos ahí, ya los manda para las dependencias donde están SEDESOL y CDI. Ya de ahí [... [ van detrás del proyecto con las copias para ver si bajan los recursos y, como siempre hay gente que nos echa la mano, por eso es que a veces van los proyectos [...] Nosotros lo manejamos directo porque ya nos pasó [...] que llegó un millón doscientos, mire que se llevaron toda la paga con las camas que nos metieron, cada cama costaba nueve mil pesos [...] Si nosotros lo hubiéramos manejado ese recurso, se hubiera comprado una buena cama queen [size] más barata y todavía nos hubiera quedado para arreglar las otras cabañas (Paulino, 11 de julio de 2012).

La obtención de recursos gubernamentales, sobre todo de la SEDESOL y de CDI, ha desarrollado en los líderes la capacidad para establecer relaciones de complementariedad y enraizamiento con distintas organizaciones públicas, así como lograr equilibrios para asegurar el desarrollo de El Madresal. Al mismo tiempo que requieren el respaldo de las autoridades municipales, luchan por manejar de manera autónoma los recursos que obtienen de instituciones federales y estatales. También han aprendido a apoyarse en las agencias de desarrollo comunitario, organizaciones no gubernamentales de San Cristóbal de Las Casas o Tuxtla Gutiérrez que, a cambio de un porcentaje de los recursos que obtengan de los proyectos, los ayudan en aspectos tales como llenar los papeles e informarse de los proyectos estratégicos que los gobiernos estatal o federal promueven. Parte de la estrategia consiste en tener los papeles listos para postular a cualquier programa del que puedan beneficiarse, por lo que convierten en fortaleza la desventaja que los bajos niveles educativos de los miembros de la cooperativa podrían representar para ellos y el proyecto.

Los cooperativistas han aprendido a hacer un uso estratégico de los recursos tangibles e intangibles con los que cuentan, combinando las necesidades personales con las del desarrollo del proyecto. Por ejemplo, aportan los recursos del programa destinados a salarios por empleo temporal para ampliar el alcance, como la construcción de cabañas, y con ello refuerzan su credibilidad y los lazos de confianza con las agencias gubernamentales. En otra ocasión, por ejemplo, cuando accedieron por primera vez al programa Playa Limpia, ellos mismos trabajaron para tener un ingreso familiar por el trabajo; ahora, cuando obtienen recursos de estos programas contratan personas de la comunidad para llevar a cabo el trabajo. En temporada alta también acceden al programa de empleo temporal de la SEDESOL con cuyos recursos contratan de veinte a treinta personas de apoyo. En este sentido, mantener la cooperativa como un proyecto productivo colectivo crea condiciones para acceder a recursos que de otra manera difícilmente lograrían.

El trabajo de los últimos dos años se ha enfocado en ampliar el alcance regional de su servicio. El Madresal es conocido como un lugar para vacacionar en Chiapas, pero ya recibe turistas de Monterrey, México Distrito Federal, Querétaro, Puebla, Veracruz y Oaxaca. Los cooperativistas utilizan la red para promoverse ${ }^{13} y$ tienen una página en Facebook para difundir sus actividades.

\section{Aprendizaje social y sinergias para el desarrollo comunitario}

A decir de las personas entrevistadas, en los últimos treinta años Ponte Duro cambió su fisonomía: dejó de ser un pueblo con ranchitos, para convertirse en uno con casas de material que resisten más fácilmente los huracanes. El dinero para construir casas estables 
vino de la migración, aseguran, y, en efecto, como han apuntado diversos autores (Villafuerte y García, 2006, 2008 y 2014; Martínez, 2013), esto tiene una relación directa con los impactos de los huracanes. Sin embargo, nuestro estudio muestra que esos eventos devastadores intensificaron un proceso que en Ponte Duro había iniciado en la década de los ochenta por circunstancias propias de la dinámica de reproducción de la comunidad: el agotamiento de los bancos de camarón. Es claro que un estudio de caso no permite generalizaciones, pero sí abre algunas preguntas: ipor qué la gente decidió emigrar a Estados Unidos antes de que iniciaran las crisis económicas que ha vivido México desde 1982? ¿cómo se conectaron con los mercados laborales de ese país?, ¿qué influencia tuvieron los centroamericanos que cruzan por esta región en la socialización de la información y la creación de narrativas relacionadas con la migración?, ies una dinámica particular de Ponte Duro, o se expande a toda la región de la Costa? Ante lo reciente del fenómeno, todavía es posible encontrar en Estados Unidos a los migrantes pioneros que facilitaron la transnacionalización de esta comunidad, lo que abre otra veta de estudio interesante.

Este trabajo se enfoca intencionalmente en las remesas sociales y los cambios culturales, en términos de narrativas personales y aprendizajes individuales, que los migrantes trajeron consigo y se han convertido en un bien colectivo que impacta de manera positiva en el desarrollo de su comunidad a través de un proyecto productivo exitoso. Casos como éste son más la excepción que la regla por la siguiente contradicción: si se trata de remesas familiares, ipor qué se utilizan en la promoción de proyectos sociales de desarrollo comunitario? Esta discusión se ha producido desde hace más de quince años, y Castles y Delgado (2008) la sintetizan en su trabajo comparando políticas de desarrollo basadas en la migración en los cinco principales circuitos migratorios del mundo; si son remesas colectivas, ¿quién asumiría la propiedad de un proyecto productivo?, como señalan entre muchos otros Iskander (2006) o Fernández, García y Vila (2006) para analizar los impactos del Programa $3 x \mathrm{xl}$ y su fallido potencial en el desarrollo de proyectos productivos.
El caso de El Madresal es interesante porque se trata de una comunidad que, al ver cómo se agotaba el camarón, recurso de sobrevivencia básica sobre el cual habían estructurado su forma de vida y su identidad, se dio cuenta de la necesidad de cambio. La migración abrió una veta, que se sigue alimentando con la población joven y más educada formalmente, pero también porque muestra cómo se colectiviza el conocimiento adquirido a partir de las experiencias migratorias de los miembros de la cooperativa. Estas experiencias abren opciones de cambio para las personas que se atreven a salir y son obligadas a adaptarse a las circunstancias: caminar por el desierto, construir una vida como indocumentados, aprender rápidamente a realizar cualquier trabajo, organizar sus recursos para sostenerse a ellos y a sus familias en México, etcétera. Una vez que logran establecerse en un trabajo, la capacitación complementa la falta de educación formal con la que salieron de su comunidad.

Todos esos elementos de aprendizaje individual se convierten en un bien colectivo por la asociación de familiares y amigos que acuerdan reglas estrictas de colaboración y trabajo conjunto, lo que explica, junto con la capacitación, el éxito de El Madresal. Este proyecto se sostiene sobre un principio cooperativo y crea un bien colectivo basado en las sinergias de las redes sociales y familiares del grupo que lo conforma. Se refuerza con los lazos de confianza y amistad que se crean al trabajar juntos con una disposición al cambio personal que implica adaptarse al nuevo proyecto y aprender a construir una nueva identidad laboral a través de la capacitación. Hacia afuera, el proyecto se sostiene con base en las sinergias y lazos de confianza creados con distintas agencias gubernamentales que apoyan el proyecto y, al hacerlo, los actores públicos y privados refuerzan su éxito. Hasta el año 2012 en que realizamos el estudio, el proyecto había crecido con base en transferencias tangibles e intangibles del Gobierno hacia El Madresal, que se transformaba poco a poco en una empresa autónoma. Tenían entonces el reto de consolidar la autonomía y reducir la dependencia del Gobierno. 
Finalmente, son los migrantes que retornan a su comunidad, basados en sus redes familiares, los que se convierten en factor de transmisión de esa experiencia de cambio. Intencionalmente, no nos adentramos en la discusión de si son exmigrantes o migrantes de retorno, porque no está claro si han concluido o no sus proyectos migratorios, aunque con El Madresal buscan crear una alternativa a la migración, que no se ha detenido.

\section{Conclusiones}

En los primeros años de trabajo, en el Centro Ecoturístico El Madresal construyeron diecisiete cabañas y tres palapas, formaron personal competente y desarrollaron la capacidad para ofrecer empleo y un ingreso fijo semanal a los miembros de la cooperativa. En cinco años se han convertido en ejemplo para algunos miembros de la comunidad, en donde han fracasado cuatro intentos por repetir la experiencia de crear servicios de hotelería basados en el ecoturismo. En buena medida se han convertido en un motor de cambio social, cultural y económico en el desarrollo futuro de la comunidad, y también en un foco de atracción turística. Se trata de una combinación afortunada de experiencias, entre las que migrar se convirtió en una especie de escuela, de modo que la migración se ha convertido en un factor de cambio social. Por ello, en este trabajo la migración no se ve solamente como un problema que hay que detener, sino que en buena medida aportó una experiencia en la que se basaron aprendizajes individuales y colectivos que sustituyen la falta de educación formal de los cooperativistas, entre otras ventajas.

El segundo punto a destacar es el cambio que poco a poco se empieza a gestar en las relaciones de género. Las mujeres que fueron invitadas a la cooperativa "para que hagan el trabajo de las mujeres”, como nos explicó don Jorge, son ahora propietarias en igualdad de condiciones que los hombres y se capacitan y especializan como trabajadoras flexibles en las mismas circunstancias. Hombres y mujeres son propietarios del proyecto, se capacitan y transforman poco a poco sus roles e identidades tradicionales. Es interesante notar que hoy en día ellas presumen de haber salido de la cocina para volverse recamaristas y de que al menos una parte del trabajo del restaurante es estrictamente masculino: fueron los hombres los que tuvieron que aprender a trabajar de meseros y ayudantes de cocina.

Ponte Duro vive dos procesos paralelos: el abandono de su población joven y el desarrollo de un proyecto productivo como El Madresal, con el que se busca crear alternativas a la migración. No está claro cuál se impondrá en el futuro o si coexistirán. Al inicio señalamos que la población joven y más educada es la que está migrando de Ponte Duro ante la frustración por la falta de oportunidades. Los migrantes que dirigen la cooperativa también señalan que El Madresal es una oportunidad que ellos no tuvieron. Queremos ilustrar esta paradoja con una cita de Fabián, el líder de la cooperativa y exmigrante:

[El Madresal] también ha sido como una escuela de aprendizaje para nuestros hijos. Es algo nuevo para nosotros y para ellos mucho más. Pero es una fortuna, porque hubiera deseado cuando era niño o adolescente tener un empleo cerca de mi casa. Los hijos de todos los socios de aquí van a poderlo hacer [...] A mis hijos me los imagino con una empresa, siendo gerentes de su empresa, o generales, o contadores, o administradores, o guías de su empresa, o traductores. Los imagino viviendo de un patrimonio que sus padres les dejaron, ellos trabajándolo y cuidándolo para la futura generación. Así me los imagino, sobreviviendo de esto [...] Desearía que mis hijos se fueran, pero con una beca, por ejemplo, al extranjero a estudiar. Porque [vas con] lo tuyo y tu cultura y [aprendes de] la otra [cultura]. Si eres un estudiante inteligente, las amarras las dos y te haces un ser humano superdotado porque vives de dos culturas y sabes moverte en los dos medios. Eso sería muy importante y sería afortunado que lo lograran (Fabián, 16 de julio de 2012).

La diferencia es que la migración le permitió a Fabián, como a muchos otros padres de la cooperativa, crear algo 
distinto para que sus hijos tengan una oportunidad de trabajo cerca de su terruño.

\section{Notas}

1 "The potential for social remittance impact to scale up and scale out: not only do social remittances affect local-level organisational culture and practice, they can also influence regional and national changes [...] Moreover, individual and collective social remittances also strongly influence the way organised groups relate to state structures and foment 'state society-synergies" (Evans, 1996).

${ }^{2}$ Evans lo define: "Complementarity is the conventional way of conceptualizing mutually supportive relations between public and private actors. It suggests a clear division of labor, based on the contrasting properties of public and private institutions [...] 'embeddedness' that is, on ties that connect citizens and public officials across the public private divide" (1996: 179-180).

${ }^{3}$ En este trabajo utilizamos indistintamente exmigrantes y migrantes de retorno, con plena conciencia de que podríamos asumir que se ha concluido el proyecto migratorio, aunque este punto no está claro con la información recabada en el trabajo de campo.

${ }^{4}$ Esta distinción es importante porque en la discusión sobre el uso de las remesas para promover proyectos productivos se definieron dos tipos de proyectos: los proyectos sociales como los que resultan de las remesas colectivas: pavimentación de calles, drenajes, alumbrados, parques, etcétera - por ejemplo, los promovidos dentro del Programa 3xlpara migrantes$y$, por el otro lado, los proyectos productivos con fines de lucro, cuya promoción con remesas colectivas generaba conflictos irreconciliables sobre la propiedad de los mismos (Iskander, 2006; Fernández, García y Vila 2006). El hecho de que éste sea un proyecto productivo colectivo - es decir, construido con base en la Ley de Cooperativas-, con una propiedad colegiada, es una característica particular de El Madresal.

${ }^{5}$ Chiapas está integrado hoy por 123 municipios divididos en quince regiones económicas. La región de nuestro estudio es la región 9 Istmo-Costa, integrada por los municipios de Tonalá, Pijijiapan y Arriaga. Ponte Duro es un ejido/colonia del municipio de Tonalá. En 2012, el estado estaba integrado por 119 municipios divididos en quince regiones económicas (INEGI, 2012). Los municipios de la región Istmo-Costa constituían la ruta más corta de acceso al tren para los migrantes centroamericanos que buscaban llegar a Estados Unidos.

${ }^{6}$ Valdría la pena contactar con los pioneros y evaluar la influencia que tuvieron los centroamericanos en tránsito hacia el norte en la decisión de emigrar en las personas del ejido.

${ }^{7}$ A las preguntas en dónde están o a dónde fueron, las respuestas incluyeron: Chicago (Illinois), Kentucky, Las Vegas (Nevada), Houston y Dallas (Texas), Los Ángeles (California), Mississippi, New Jersey, Nueva York, Nuevo México, Ohio, Phoenix (Arizona), Wisconsin, Carolina del Norte, Carolina del Sur, Colorado, Florida e Indianápolis (Indiana).

${ }^{8}$ Los datos señalados provienen de una encuesta que levantamos en la comunidad en julio de 2012 a menos que se señale lo contrario.

9 Entre los solicitantes de matrículas consulares en 2007 originarios de Chiapas, el 20.56\% contaba con certificado de primaria terminada, el $32.7 \%$ con secundaria terminada y el $15.2 \%$ con preparatoria terminada (SRE, 2007), en un estado con un 18\% de la población analfabeta (INEGI, 2011).

${ }^{10}$ Es altamente probable que los datos no coincidan con los procesos reales de formalización del ejido y dotación de tierra porque la información está basada en los testimonios de las dos personas de mayor edad del ejido, que al momento de la entrevista tenían más de 80 años y forman parte de la primera generación que nació en Ponte Duro. No revisamos los archivos agrarios porque la historia del proceso agrario de formalización del ejido no era importante para los fines de nuestro estudio.

"Según relatan, cuando se consiguieron las tierras no sabían qué nombre poner al ejido: "El nombre de Ponte Duro se eligió porque entre octubre y noviembre sopla el viento del norte, y una vez venían dos embarcaciones 
con familias, andaban en canoas, y venía uno parado. Venían las dos canoas a esperar al tren y empezó el aire a soplar y el que venía adelante les dice 'hermano ya viene el norte, ponte duro' para que no lo tirara, 'ponte duro, no te caigas...' Y esa es la historia de por qué le pusieron así al ejido y ya no se le quitó. Cuando cambiaron de presidente [y regularizaron las tierras] le pusieron Manuel Ávila Camacho, pero la gente sigue usando Ponte Duro.

${ }^{12}$ Este dato cobra importancia porque en 2012 solamente trece personas tenían un trabajo formal que les permitía estar inscritas al IMSS, al ISSSTE o al servicio médico de las fuerzas armadas. En solamente diez años, el Gobierno federal afilió a este servicio a prácticamente toda la población.

${ }^{13}$ Ver: https://www.elmadresal.com.

\section{Referencias bibliográficas}

Bellinghausen, H. (2008). "Empuje interesado del ecoturismo en Chiapas", en La Jornada, 17 de abril.

Castles, S y Raul Delgado Wise (2008). Migration and Development: Perspectives from the South. Ginebra: IOM/ UAZ/RIMD.

Durand, J. y Douglas S. Massey (2003). Clandestinos. Migración México-Estados Unidos en los albores del siglo XXI. México: Universidad Autónoma de Zacatecas/ Miguel Ángel Porrúa.

Evans, P. (1996). "Government Action, Social Capital and Development: Reviewing the Evidence on Synergy". En World Development, vol. 24, núm. 6, pp. 178-209.

Fernández, R., Rodolfo García Zamora y Ana Vila Freyer (coords.) (2006). El Programa 3xl para Migrantes. ¿Primera política transnacional en México? México: Universidad Autónoma de Zacatecas/Instituto Tecnológico Autónomo de México/Miguel Ángel Porrúa.

INEGI (2001). Censo General de Poblacióny Vivienda. México: INEGI. Disponible en: http://www.inegi.org.mx/est/ contenidos/Proyectos/ccpv/cpv2000/default.aspx.

INEGI (2011). Censo General de Población y Vivienda. México: INEGI. Disponible en http://www.inegi.org.mx/est/ contenidos/proyectos/ccpv/cpv2010/Default.aspx.
INEGI (2012). Perspectiva estadística de Chiapas. México: INEGI. Disponible en: http://www.inegi.org.mx/ prod_serv/contenidos/espanol/bvinegi/productos/ integracion/estd_perspect/chis/Pers-chs.pdf (consultado el 2 de diciembre de 2015).

Iskander, Natasha (2006). "Social Learning as a Productive Project: The Tres Por Uno (Three for One) Experience at Zacatecas, Mexico". En The Development Dimension. Migration, Remittances and Development. S.l: OECD, pp. 249-263. Disponible en: http://dx.doi. org/10.1787/9789264013896-18-en.

Levitt, P. y Deepak Lamba-Nieves (2011). "Social Remittances Revisited". En Journal of Ethnic and Migration Studies, vol. 37, núm. 1, enero, pp. 1-22.

Martínez, G. (2013). "Migración internacional chiapaneca: trayectorias de movilidad, sociodemográficas y condiciones sociales". En Revista Pueblos y Frontera Digital, vol. 8, núm. 15, junionoviembre, pp. 50-91.

SRE (Secretaría de Relaciones Exteriores) (2007) "Matrículas consulares expedidas a originarios de Chiapas por nivel de educación en los consulados de México en EE.UU., 2006". México: SER. Disponible en: http.//www.ime.gob.mx (consultado el 23 de septiembre de 2010).

Vila Freyer, Ana (2013). "De la vulnerabilidad extrema a la inclusión transnacional Movilidad laboral de Chiapas 1995-2010". En María Eugenia Anguiano y Rodolfo Cruz (coords.), Migraciones internacionales, crisis y vulnerabilidades: perspectivas comparadas. Tijuana, México: El Colegio de la Frontera Norte.

Villafuerte Solís, Daniel y María del Carmen García Aguilar (2008). "Algunas causas de la migración internacional en Chiapas”. En Economía y Sociedad, vol. XIV, núm. 2l, enero-junio, pp. 4l-58.

Villafuerte Solís, Daniel y María del Carmen García Aguilar (2006). "Crisis rural y migraciones en Chiapas”. En Migración y Desarrollo, núm. 6, primer semestre, pp. 102-129.

Villafuerte Solís, Daniel y María del Carmen García Aguilar (2014). "Tres ciclos migratorios en Chiapas: interno, regional e internacional”. En Migración y Desarrollo, vol. 12, núm. 22, pp. 3-38. 